\title{
RHEUMATIC PERICARDITIS
}

\author{
BY \\ G. T. THOMAS, E. M. M. BESTERMAN, AND A. HOLLMAN \\ From the Special Unit for Juvenile Rheumatism, Canadian Red Cross Memorial Hospital, Taplow, Bucks
}

Received August 8, 1952

Opinions on prognosis in rheumatic pericarditis have differed widely. The same may be said of other and less important aspects: its frequency (Schlesinger, 1938; Ash, 1942); the sex and age incidence (Coombs, 1924; Findlay, 1932); the interval after the onset of the rheumatic state before it develops (Gibson, 1936); and the frequency of electrocardiographic changes (Bellet, 1938; Nay, 1949; Wood, 1950). We have studied these points and have found striking differences between them in cases with dry pericarditis only and in those with effusion. In the past, little or no attempt has been made to distinguish between these two types, and this may account for many of the discrepancies in the findings. One object of this paper, therefore, is to emphasize what differences there are between dry pericarditis and pericarditis with effusion. Cases with effusion have also been studied in detail to determine any specific clinical features that they may show, to see what clinical signs occur most frequently and which of them appear early and are therefore most useful in diagnosis, and to correlate the electrocardiographic changes with alterations in size of the effusion.

\section{A Comparison between Dry Pericarditis and Pericarditis with Effusion}

Altogether there were 38 cases in the series: 30 of them had effusion, and 8 had dry pericarditis only. The sex and age incidence was somewhat different in the two. Effusion occurred with equal frequency in the two sexes and the two age groups, five-ten and eleven-fifteen years, whereas dry pericarditis was more common in boys between eleven and fifteen (Table I). These differences, however, are not statistically significant.

All 8 cases with dry pericarditis survived; 15 of the 30 with effusion died (Table I). This difference is not likely to occur by chance alone $\left(\mathrm{x}^{2}=6.6 ; \mathrm{P}=0.01\right)$, but may be explained by differences in the duration of preceding rheumatic activity in the two groups (see below).

TABLE I

The Sex and Age Incidence and Mortality in Pericarditis-with and without Effusion

\begin{tabular}{|c|c|c|c|c|c|c|c|c|c|}
\hline \multirow{2}{*}{\multicolumn{3}{|c|}{ Type of pericarditis }} & \multirow{2}{*}{$\begin{array}{c}\text { Number } \\
\text { of } \\
\text { cases }\end{array}$} & \multicolumn{2}{|c|}{ Sex } & \multicolumn{3}{|c|}{ Age (in years) } & \multirow{2}{*}{$\begin{array}{c}\text { Number } \\
\text { of } \\
\text { deaths }\end{array}$} \\
\hline & & & & Boys & Girls & $5-10$ & $11-15$ & $16-20$ & \\
\hline With effusion & .. & . & 30 & 15 & 15 & 16 & 13 & 1 & 15 \\
\hline Without effusion & . & . & 8 & 6 & 2 & 1 & 6 & 1 & 0 \\
\hline
\end{tabular}


More detailed comparison between the two types was possible in only 17 of the 30 with effusion and 7 of the 8 with dry pericarditis, for in the remainder the onset of pericarditis preceded admission to this hospital and the previous data were inadequate. In all 7 cases with dry pericarditis, pericardial friction developed during the first month of rheumatic activity, whereas 12 of the 17 effusions occurred after the end of the first month, and 3 of them after the end of the sixth month or later. The duration of preceding rheumatic activity had a direct bearing on the outcome of cases with effusion, for the 5 in which the effusion developed during the first month all survived, whereas 10 of the 12 that developed later died. Pericardial friction was heard in the "dry " cases for between two and twenty-four days, in 5 of them for four days or less. Effusion, on the other hand, persisted for two months or more in 6 of the 7 cases that survived; though in the seventh it resolved in a month. Other differences between the two groups of case were as follows. Abnormal electrocardiograms were found in 10 of the 17 with effusion, whereas the curves were invariably normal in dry pericarditis. Pain was more common in effusion that in dry pericarditis, being present in 13 with effusion and in only 2 with dry pericarditis. Tachypnœa, with rates from 40 to 70 a minute, occurred in all cases with effusion, but was never observed with dry pericarditis. The white count ranged between 13,000 and 30,000 in all but one case with effusion, and was below 13,000 in 6 of the 7 with dry pericarditis. Residual heart lesions were present in 6 of 7 cases with effusion that survived and in only 4 of the 7 with dry pericarditis.

These differences between cases with dry pericarditis only and those with effusion may well account for many of the discrepancies in the findings of previous series, for in none of them have the two types of case been differentiated. Thus Schlesinger (1938) found a mortality rate of 33 per cent and Ash (1942) of 60 per cent. In our own series there was no mortality rate for dry pericarditis; for effusion it was 50 per cent. Gibson (1936) stated that most cases occurred within two weeks of the onset of the rheumatic state. All our cases of dry pericarditis occurred during the first month: 12 of the 17 with effusion developed later. Findlay (1932) and Ash both found that a small proportion of their cases recovered without residual valve lesion- 2.9 and 2.5 per cent respectively. Only 1 of our 7 effusions that survived had no residual lesion, whereas 3 of the 7 with dry pericarditis had normal hearts on discharge. Nay (1949) reported abnormal electrocardiograms in all his cases; Wood (1950) in only a quarter. All our cases with dry pericarditis had normal curves: 10 of the 17 effusions had abnormal curves.

Dry pericarditis appeared to be relatively benign: it invariably occurred during the first month of rheumatic activity, caused no electrocardiographic changes, was of short duration, and had no effect on prognosis. Effusion, on the other hand, occurred at any time during the course of the disease, frequently caused cardiographic changes, persisted for several weeks, and usually affected the prognosis adversely.

\section{Seventeen Cases with Effusion}

The clinical and electrocardiographic findings, the results of therapy, and the prognosis in 17 cases with effusion will now be described in detail.

The temperature at the onset of the effusion ranged between $101^{\circ}$ and $104^{\circ} \mathrm{F}$. Tachypnœa was invariable; it could not be accounted for by the size of the effusion, the size of any accompanying pleural effusion or by the presence of pain. In 7 cases it preceded clinical and radiographic signs of effusion, and in 3 it persisted until the effusion had diminished in size or had disappeared. Thirteen cases had pain; 11 of them for one day only, the other 2 for seven days. In the majority the pain was described as a substernal ache, aggravated by respiration and movement. The remainder had pain in the left shoulder and/or the left chest on breathing. The sedimentation rate was raised in all cases, in half of them to over $100 \mathrm{~mm} /$ hour (Westergren). The white blood count was raised as described.

A Correlation of the Clinical and Radiological Signs. In 15 of the 17 cases skiagrams had been taken at intervals of not more than a week throughout the course of the effusion and it was possible to correlate 
the clinical with the radiological signs (Table II). In four cases abnormal physical signs were present before there was any certain X-ray evidence of effusion: 3 of them had a raised venous pressure and 3 had abnormal signs in the lung bases. At a time when skiagrams first showed effusion the most frequent abnormal findings were signs at the lung bases (14 cases), raised venous pressure (13 cases) and increased cardiac dullness (10 cases). Enlargement of the liver was present in only 4 cases but developed later in

TABLE II

Clinical Signs in 15 Cases of Rheumatic Pericardial Effusion

\begin{tabular}{|c|c|c|c|c|c|}
\hline \multirow{2}{*}{\multicolumn{2}{|c|}{ Signs }} & \multicolumn{2}{|c|}{$\begin{array}{c}\text { Number of cases showing each } \\
\text { of the various signs }\end{array}$} & \multirow{2}{*}{$\begin{array}{l}\text { Number of } \\
\text { cases } \\
\text { developing } \\
\text { various } \\
\text { physical } \\
\text { signs } \\
\text { later }\end{array}$} & \multirow{2}{*}{$\begin{array}{l}\text { Number of } \\
\text { cases that } \\
\text { ultimately } \\
\text { showed } \\
\text { each of } \\
\text { the various } \\
\text { signs }\end{array}$} \\
\hline & & $\begin{array}{l}\text { When } \\
\text { no certain } \\
\text { X-ray } \\
\text { evidence of } \\
\text { effusion }\end{array}$ & $\begin{array}{l}\text { When } \\
\text { X-rays } \\
\text { first } \\
\text { showed } \\
\text { effusion }\end{array}$ & & \\
\hline $\begin{array}{l}\text { Raised venous pressure } \\
\text { Abnormal signs at lung bases } \\
\text { Abnormal cardiac dullness } \\
\text { Pericardial friction } \\
\text { Enlargement of the liver } \\
\text { Diminished heart sounds } \\
\text { Diminished apex beat ... }\end{array}$ & $\begin{array}{ll}. & \cdots \\
\cdots & \cdots \\
\cdots & \cdots \\
\cdots & \cdots \\
\cdots & \cdots \\
\cdots & \cdots \\
\cdots & \cdots\end{array}$ & $\begin{array}{l}3 \\
3 \\
1 \\
1 \\
1 \\
0 \\
0\end{array}$ & $\begin{array}{r}13 \\
14 \\
10 \\
9 \\
4 \\
4 \\
4\end{array}$ & $\begin{array}{l}2 \\
0 \\
2 \\
2 \\
4 \\
0 \\
0\end{array}$ & $\begin{array}{r}15 \\
14 \\
12 \\
11 \\
8 \\
4 \\
4\end{array}$ \\
\hline
\end{tabular}

another 4. The frequency with which the various physical signs were ultimately found is shown in the last column of the table.

It is concluded that the most frequent signs of rheumatic pericardial effusion are raised venous pressure, signs at the lung bases, and abnormal cardiac dullness. The first two of these are early signs and may precede X-ray evidence of effusion. Liver enlargement is a less common sign and frequently a late one. Diminished intensity of heart sounds and disappearance of the apex beat are noticeable in only a minority of cases.

Regression of Physical Signs. Seven cases died. In the remaining 8 the regression of physical signs was observed as the skiagrams returned to normal. Signs to disappear early were raised venous pressure, pericardial friction, signs at the right base, diminished heart sounds, disappearance of the apex beat, and dullness beyond the apex beat: dullness in the second left space tended to persist, as did enlargement of the liver. In 6 cases the last abnormal findings were signs at the left base.

Though there was on the whole good correlation between regression of clinical signs and return of the skiagrams to normal, there were certain discrepancies. In 4 cases abnormal signs at the bases, and in one abnormal cardiac dullness persisted after the skiagrams had become normal. In another, all clinical signs had disappeared and yet the skiagram still showed a small effusion.

Signs at the Lung Bases. Signs at the lung bases were present in 14 out of the 15 cases; they preceded $\mathrm{X}$-ray evidence of effusion in 3 and persisted after the skiagrams had returned to normal in 4 . They will be considered, therefore, in detail.

All 14 cases had signs at the left base and 13 had signs at the right as well. Of those with bilateral signs, 6 developed them first in the left side, and 2 in the right; in the other 5 both sides became implicated simultaneously. The signs at the left base were invariably more extensive than those at the right and always suggested the presence of fluid; pleural rubs were heard in 3 cases. The signs at the right base were similar to those at the left in 6; in the remainder there was only dullness to percussion. Pleural rubs were heard in 3 cases.

The presence of fluid at the left base was confirmed by X-rays in all cases, and by paracentesis in three. In 12 of the 13 cases with signs at the right base there was also radiographic evidence of effusion, but to a lesser degree than on the left side. In all cases the physical signs were more obvious than the X-ray changes, and in many the presence of fluid could be demonstrated only by films taken in the oblique positions. Collapse of a lower lobe was not observed: if it occurred, it was obscured by the presence of fluid.

It is concluded that signs at the lung bases are due usually to accompanying pleural effusions: collapse 
of a lower lobe is uncommon and, it is believed, occurs only under special circumstances such as secondarily to a large pleural effusion or to a purulent bronchitis, as in two recent cases. The suggestion made by Poynton (1921), that basal signs are due to compression collapse, could not be confirmed.

Electrocardiographic Findings. Electrocardiograms had been taken at weekly intervals in all but 2 of the 17 cases; in 10 they were abnormal, in 6 they were normal, and in 1 the changes were of doubtful significance.

Ten cases with Abnormal Cardiograms. The time of onset of the cardiographic changes were as follows: in 1 case S-T elevation was the first evidence of pericarditis; in 3 the curves became abnormal as clinical and X-ray signs of effusion appeared; in 5 they did not become abnormal until three to eight days after a diagnosis of effusion had been made by other means. In the remaining case the cardiogram was already abnormal and accompanied clinical and X-ray evidence of effusion when the patient was admitted.

The most frequent initial cardiographic change was S-T elevation, which was present in 6 cases: it was seen in leads I, II, VL and V6 in three of them, in leads II and VL in two, and in lead III only in one. The segment was saddle-shaped in three cases, normal in two, and coved in one. The next most frequent was a low $T$ wave in all leads; this was present in three cases. The least frequent was $T$ wave inversion, which was found in only one case in leads II and III.

The subsequent behaviour of the cardiogram showed considerable variation in the 10 cases, particularly when considered in relation to changes in size of the effusion: in 2 cases the curves returned to normal as the effusion increased (Fig. 1); in 2 they became normal, the size of the effusion remaining unchanged; in 6 they underwent changes over periods of two to six weeks as the effusion first increased and then diminished.

The two cases in which the curves returned to normal as the effusion increased in size showed S-T elevation for three and five days only. One died when the effusion was at its height; the curve on the day of death was normal. The other survived, and the curve remained normal apart from $\mathrm{T}$ wave inversion in V5 on one occasion.

Of the two cases in which the curves became normal without any change in size of the effusion, one had S-T elevation for three days, the other low $\mathrm{T}$ waves for fourteen days. Both died: in one of them normal curves had been found on four occasions during the month preceding death; the diagnosis were confirmed at autopsy.

Three of the six cases with more persistent cardiographic changes had initial S-T elevation. In only one did the segment remain elevated as the effusion increased in size (Fig. 2); in the other two the S-T elevation disappeared and the $T$ waves became low (Fig. 3). Two cases had initial low $T$ waves. In one the $T$ waves became flattened as the effusion increased; in the other the T wave in V5 became inverted. The sixth case had normal cardiograms until the effusion was maximal; there was then $T$ wave inversion in leads II and III. In all six cases the curves returned to normal over periods of two to six weeks as the effusions diminished in size. All showed low $\mathrm{T}$ waves during this time; in two of them only there was late, transitory $\mathrm{T}$ wave inversion in leads I and V5 respectively.

Six cases with Normal Cardiograms. In 6 cases the curves were normal. Four had had digitalis which might have masked the changes from pericarditis. The remaining two had not had digitalis, but in one of them only one cardiogram had been taken, and in the other, they had been done at only monthly intervals. Abnormalities may well have been missed, for as it has been shown, the changes may be both delayed in the time of their appearance and of only short duration.

It is concluded that abnormal electrocardiograms will be found in rheumatic pericardial effusion, provided records are taken at intervals of not less than one week from the time of onset of the pericarditis and that the patients are not taking digitalis.

\section{RESUltS OF THERAPY}

Eight patients were treated with salicylates. Three of them died within three weeks of starting treatment. Of the five that survived, the clinical and radiological signs of effusion increased during therapy in two; in another two the signs of effusion were much less after ten days, but similar improvement was seen in an untreated case. The fifth showed a reduction in the size of the effusion after four days. Such rapid improvement was not observed in untreated cases, and it is possible that salicylates may have had some beneficial effect.

The pericardial sac was aspirated in one case only, a boy of twelve with a massive effusion; 15 and $20 \mathrm{oz}$. 
of blood-stained fluid were removed on two occasions, but only a temporary fall in the respiration rate resulted, and death occurred a few days later.

In one case with marked dyspnoea and a large left-sided pleural effusion a pint of fluid was aspirated from the pleural cavity and considerable relief was obtained.

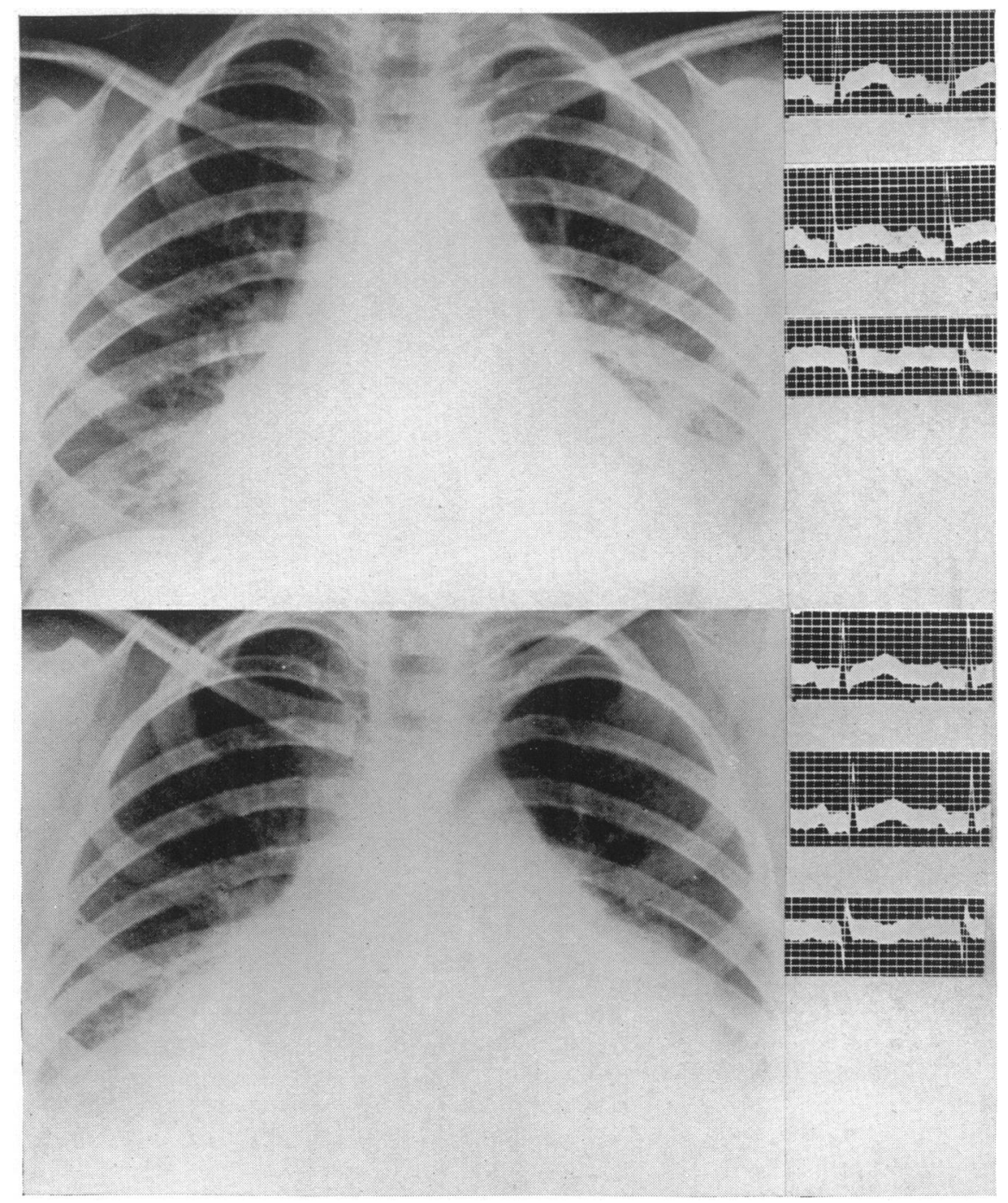

Fig. 1.-Skiagrams and standard limb leads at a week's interval to show return of electrocardiogram to normal as effusion increases in size.

\section{Prognosis}

Ten out of 17 cases died. Eight of them were between the ages of five and ten, and all had had persistent rheumatic activity for many weeks or months prior to the onset of effusion. Of the 7 that survived, only one was under ten, and five had developed effusion during the first month of rheumatic activity. Thus the prognosis was worse in patients under ten years of age and after long-continued rheumatic activity.

All but one of the 7 cases that survived had residual heart lesions. In two, both mitral and aortic 
incompetence were already present on admission. Of the other 4 , one of whom had aortic incompetence on admission, all developed signs of mitral incompetence and one those of aortic incompetence as well. Significant murmurs did not appear in two of them until the effusion had been present for some time. In the remaining case pericardial effusion was not accompanied by other evidence of carditis; at no time were significant murmurs heard, and the heart appeared to be normal one year later.

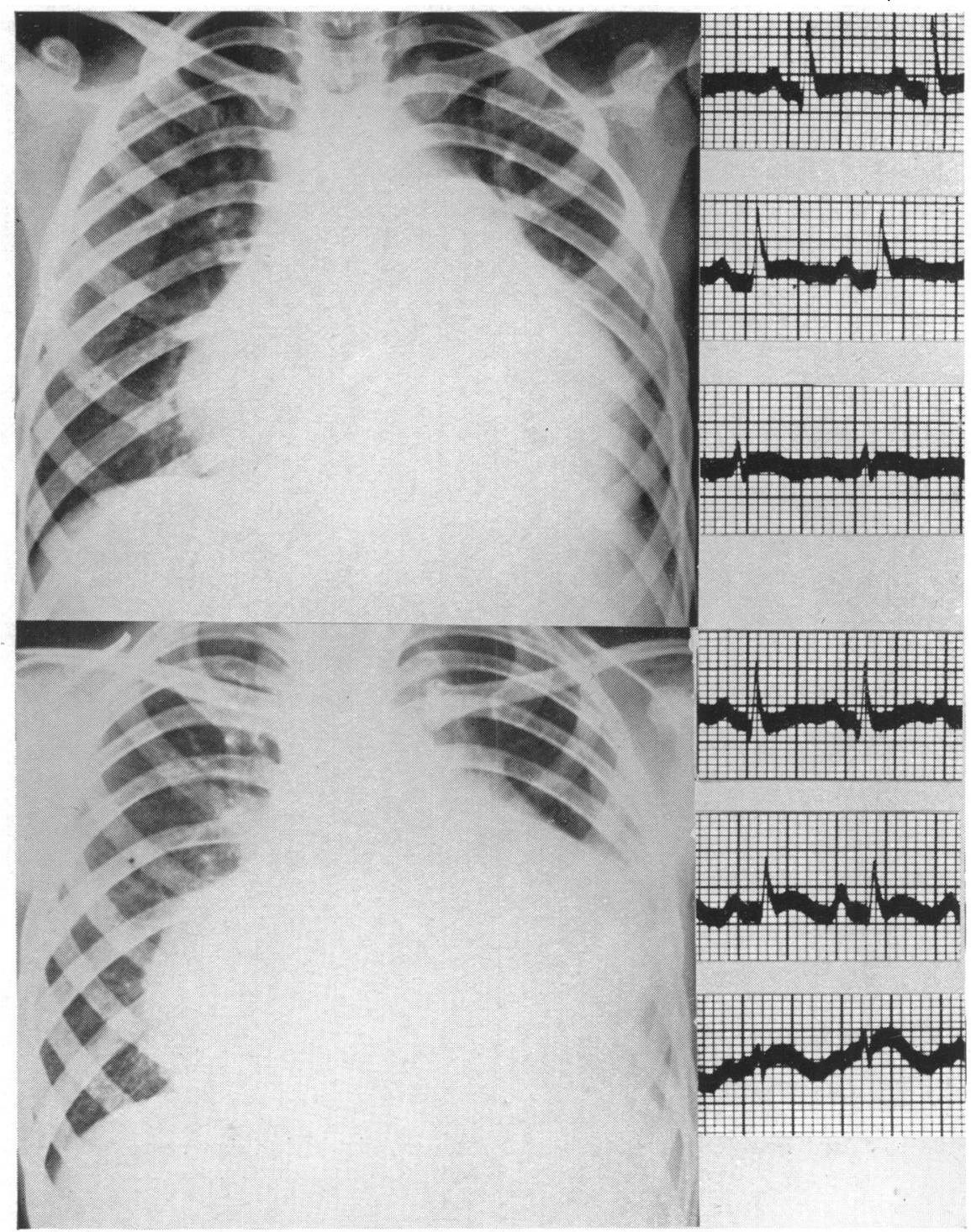

FIG. 2.-Persistent S-T elevation as effusion increases in size.

\section{Summary AND Conclusions}

Thirty-eight cases of rheumatic pericarditis have been studied, 30 of them with effusion and 8 with dry pericarditis only. The importance of distinguishing between these groups has been emphasized: dry pericarditis is a relatively unimportant feature of early carditis; effusion is a 
manifestation of severe carditis, occurring at any time during the course of the illness and affecting the prognosis adversely.

The clinical findings have been correlated with the $\mathrm{X}$-ray changes in 15 cases with effusion.

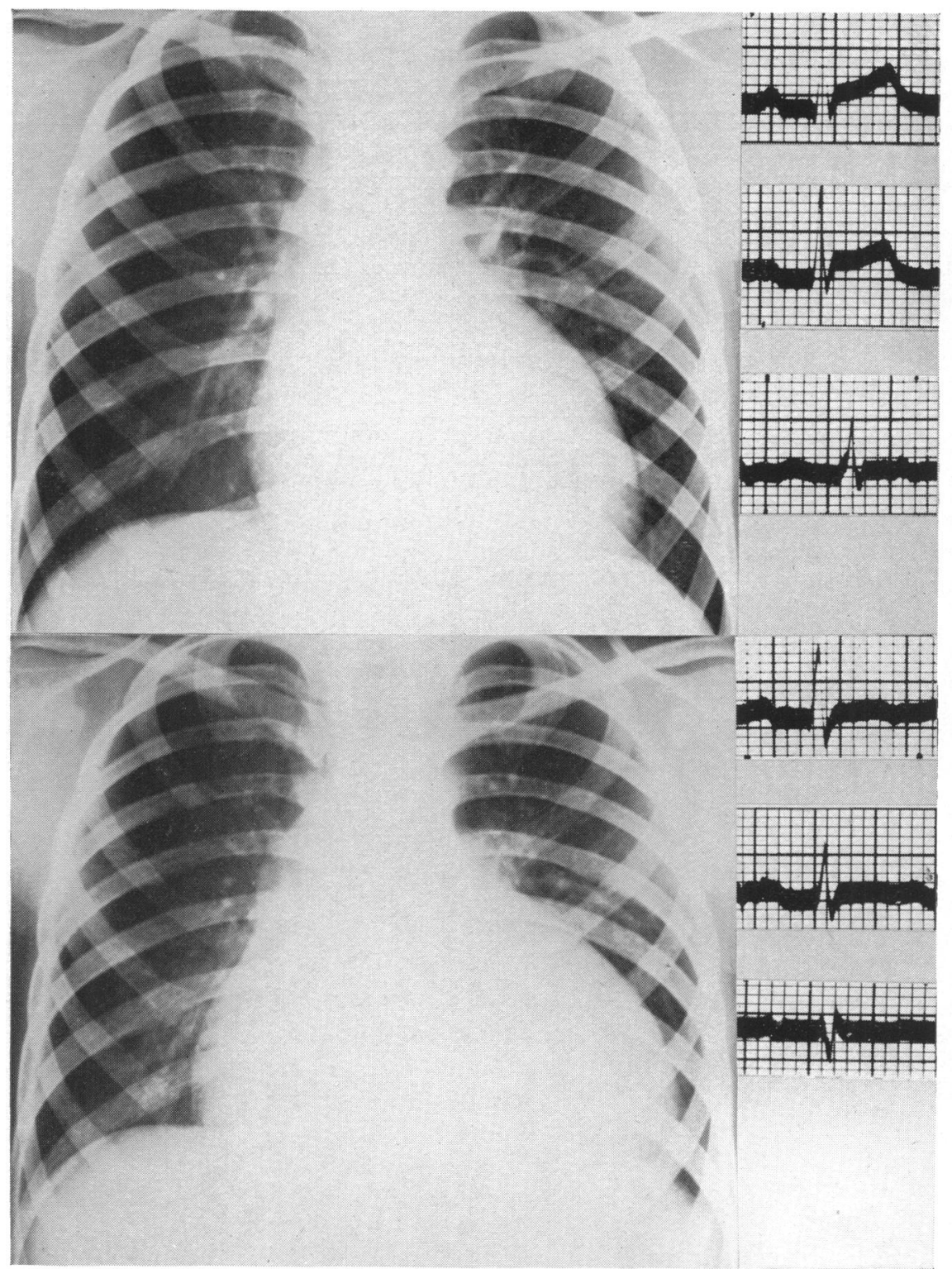

FIG. 3.-Return of S-T segment to normal and development of low or inverted T waves as effusion increases.

Raised venous pressure, signs at the lung bases, and abnormal cardiac dullness were the most common signs, the first two being early and tending to precede X-ray evidence of effusion. Signs at the lung bases could invariably be accounted for by accompanying pleural effusion.

Abnormal electrocardiograms were found in 10 of 17 cases with effusion. Changes were late in five of them, and of only short duration in four. Elevation of the S-T segment was the most 
common abnormality. Conspicuous inversion of the $\mathrm{T}$ wave was rare. Four out of six cases with normal curves had had digitalis, and this may have obscured the characteristic pattern of pericarditis. In the remaining two cardiograms had been taken at relatively infrequent intervals, and abnormalities may have been missed.

Eight cases with effusion were treated with salicylates, only one of them with possible benefit. Pleural and pericardial paracentesis were indicated and undertaken in one case each.

The prognosis in cases with effusion was worst in children under the age of ten and when there had been long-continued rheumatic activity. Ten out of 17 cases died. Of those that recovered, all but one had signs of residual heart damage: four had mitral and aortic lesions; two had mitral incompetence. The remaining case had no abnormal physical signs at the time of discharge from hospital or at follow-up examination one year later.

We are indebted to Dr. E. G. L. Bywaters and to Dr. Paul Wood for much helpful criticism and advice.

\section{REFERENCES}

Ash, R. (1942). Amer. J. Dis. Child., 63, 1.

Bellet, S., and McMillan, T. M. (1938). Arch. intern. Med., 61, 381.

Coombs, F. (1924). Rheumatic Heart Disease. John Wright \& Sons, Bristol.

Findlay, L. (1931). Rheumatic Infections in Childhood. Arnold, New York.

Gibson, S., and Denenholz, E. J. (1936). J. Pediat., 9, 505.

Nay, R. M. (1949). J. Indiana med. Ass., 42, 222.

Poynton, F. J. (1921). Brit. med. J., 2, 583.

Schlesinger, B. (1938). Lancet, 1, 593.

Wood, P. (1950). Diseases of the Heart and Circulation. Eyre \& Spottiswoode, London. 